\title{
STRATEGI PENGEMBANGAN MUTU IKAN ASIN JAMBAL ROTI (IKAN MANYUNG) DI KARANGSONG KABUPATEN INDRAMAYU
}

\author{
Talim Sumarno ${ }^{1 \star}$, Tri Winarni Agustini ${ }^{2}$, Azis Nur Bambang ${ }^{2}$ \\ ${ }^{1}$ Program Studi Magister Manajemen Sumber Daya Pantai, Universitas Diponegoro \\ ${ }^{2}$ Fakultas Perikanan dan Ilmu Kelautan, Universitas Diponegoro \\ *Korespondensi: sumarnotalim5@gmail.com \\ Diterima: 21 Mei 2020/Disetujui: 22 Juni 2020
}

Cara sitasi: Sumarno T, Agustini TW, Bambang AN. 2020. Strategi pengembangan mutu ikan asin jambal roti (ikan manyung) di Karangsong Kabupaten Indramayu. Jurnal Pengolahan Hasil Perikanan Indonesia. 23(2): 196-205.

\begin{abstract}
Abstrak
Usaha pengolahan ikan asin jambal roti di Karangsong Kabupaten Indramayu merupakan usaha yang masih tradisional, sehingga perlu penanganan, pengolahan dengan penerapan sistem manajemen mutu dan standardisasi mutu hasil perikanan. Penelitian ini bertujuan untuk menentukan strategi yang sesuai untuk mengembangkan mutu ikan asin jambal roti di Karangsong Kabupaten Indramayu. Metode analisis yang digunakan adalah kombinasi SWOT dan QSPM. Responden kunci, terdiri atas pengawas perikanan, pembina mutu provinsi/daerah, pembina UMKM pengolah perikanan, akademisi dan konsumen. Dari hasil analisis diperoleh lima alternatif strategi pengembangan dengan urutan prioritas : (1) meningkatkan kualitas produk dan mutu pelayanan kepada konsumen; (2) penguatan dan pengembangan kelompok pengolahan ikan secara terpadu; (3) melakukan sosialisasi dan pelatihan terkait SKP/SNI; (4) mempermudah akses administrasi industri pengolahan ikan UMKM; dan (5) mencari mitra usaha untuk pengembangan usaha.
\end{abstract}

Kata kunci: ikan asin jambal roti, Karangsong, pengembangan mutu, SWOT-QSPM

\section{Strategy for Quality Development of Salted Jambal Roti (Aarid catfish) in Karangsong, Indramayu}

Abstract

Jambal roti salted fish processing in Karangsong, Indramayu District is still a traditional business. Thus their handling and processing need to implement a quality management system for standardizing the quality of the products. This study was aimed to analyze a strategy fo developing high quality of salted jambal roti in Karangsong, Indramayu District. The analysis used a combination of SWOT and QSPM. Key respondents were fishery supervisors, provincial/regional quality mentors, SME supervisors, academics and consumers. Five alternative development strategies were proposed to develop high quality of jambal roti. These five strategies are (1) improving product quality and service quality to consumers; (2) strengthening and developing integrated fish processing groups; (3) socializing and training related to Indonesian National Standard (INS); (4) facilitating the administration of the MSME fish processing industry; and (5) looking for business partners for business development.

Keywords: salted jambal roti, Karangsong, quality development, SWOT-QSPM,

\section{PENDAHULUAN}

Kabupaten Indramayu khususnya di kecamatan Karangsong merupakan penghasil ikan manyung (Arius thalassinus). Hasil produksi ikan manyung di Kabupaten Indramayu mencapai rata rata 5000 ton/ tahun. Ikan asin jambal roti adalah salah satu hasil olahan ikan asin yang sangat terkenal, yang menjadi salah satu produk unggulan di Kabupaten Indramayu (Dinas Perikanan dan Kelautan Kabupaten Indramayu 2018). Ada dua jenis kualitas yang dihasilkan oleh pengolah ikan asin jambal roti yaitu kualitas super dan biasa, kualitas super dihasilkan dari 
bahan baku yang diperoleh dari penangkapan one day fishing (ikan segar), sedangkan yang kualitas biasa dihasilkan dari bahan baku yang telah mengalami pembekuan.

Hasil penelitian menunjukkan bahwa karakteristik organoleptik jambal roti terbaik diperoleh pada konsentrasi garam sebanyak 30\% dengan waktu fermentasi selama 24 jam (Rochima 2005), sebaliknya hasil penelian Akbardiansyah et al. (2018) menggunakan ikan kambing kambing (Canthidermis maculata) pada konsentrasi garam 15\% dengan waktu fermentasi 24 jam merupakan perlakuan terbaik dan sesuai dengan persyaratan mutu SNI 8273:2016. Hasil penelitian Maulid dan Abrian (2020) pada ikan jambal roti yang diambil dari Pangandaran mendapatkan kadar garam yang berkisar $10-12 \%$ dengan kadar air yang lebih dari 40\%. Persyaratan mutu dan keamanan ikan asin jambal roti yang sesuai dengan SNI 8376:2017 adalah kadar garam berkisar 15$20 \%$, sedangkan kadar air maksimal $50 \%$.

Terdapat lima pengolah ikan asin jambal roti skala usaha kecil menengah di Karangsong yang melakukan proses produksinya secara turun temurun dan masih bersifat tradisional. Proses dan teknik pengolahan ikan yang sudah dikenal di masyarakat secara tradisional yaitu penggaraman atau lebih dikenal dengan istilah ikan asin. Pada prinsipnya pengolahan ikan asin dilakukan untuk menghentikan atau menghambat pertumbuhan mikroorganisme dan aktivitas enzim pada tubuh ikan yang dapat menyebabkan kerusakan.

Kegiatan pengolahan hasil perikanan memegang peranan penting dalam kegiatan pascapanen, karena hasil perikanan merupakan komoditas yang sifatnya mudah rusak (Paladini et al. 2019). Diperlukan penanganan yang cepat dan tepat untuk menjaga mutunya, hingga produk sampai ke tangan konsumen. Kendala yang dihadapi pengolah ikan asin pada umumnya dilakukan dalam skala kecil, menggunakan teknologi tradisionalyangdidapat secara turun menurun, sanitasi dan higiene yang kurang diperhatikan terutama oleh UMKM, sehingga mutu dan daya tahan ikan asin menjadi kurang baik. Hal tersebut tentunya harus diatasi dengan cara terus mendorong dan mengembangkan
UMKM pengolahan ikan, agar memiliki mutu yang baik, aman dikonsumsi, tersedia secara berkesinambungan, berdaya saing dan sesuai dengan selera masyarakat (Liufeto et al. 2016).

Sesuai dengan amanat Undang-Undang Nomor 45 Tahun 2009 tentang Perubahan Atas Undang-Undang Nomor 31 tahun 2004 tentang Perikanan Pasal 20 ayat (3), bahwa setiap orang yang melakukan penanganan dan pengolahan ikan wajib memenuhi dan menerapkan persyaratan kelayakan pengolahan ikan, sistem jaminan mutu dan keamanan hasil perikanan, dan ayat (4) bahwa setiap orang yang memenuhi dan menerapkan persyaratan kelayakan pengolahan ikan sebagaimana dimaksud ayat (3), memperoleh Sertifikat Kelayakan Pengolahan (SKP). Peraturan dan kebijakan tentang penerapan SKP tercantum dalam Permen KP 172019 tentang persyaratan dan tata cara penerbitan SKP, namun pada kenyataannya tidak semua pengolah ikan menerapkan jaminan mutu apalagi di sektor usaha kecil menengah.

Produk ikan asin jambal roti termasuk produk andalan dan ekonomis tinggi di Indramayu, khususnya di Karangsong. Produk tersebut juga memiliki spesifikasi produk tersendiri, yang menjadi ciri khas produk olahan ikan di Indramayu. Akan tetapi kegiatan usaha tersebut masih memiliki kelemahan, yaitu masih diolah dengan sangat sederhana serta tidak memiliki jaminan mutu produk. Amanat Undang-Undang Nomor 45 Tahun 2009 tentang Perubahan Atas UndangUndang Nomor 31 tahun 2004 tentang Perikanan Pasal 20 ayat (3) belum dijalankan oleh para pengolah ikan asin jambal roti.

Beberapa kasus pada UMKM yang telah dilaporkan di antaranya adalah penerapan program kelayakan dasar GMP dan SSOP pada UMKM ikan teri dengan kondisi dan tata letak bangunan, pengolahan limbah padat, manajemen lingkungan dan manajemen personal belum memenuhi syarat (Amin et al. 2018), uji kelayakan industri pindang tongkol yang juga masih ditemukan beberapa penyimpangan (Anggraeni et al. 2019), serta indeks keberlanjutan rata-rata usaha ikan asin jambal roti di Indramayu yang kurang berkelanjutan (Niken et al. 2019). Berdasarkan permasalahan tersebut, maka 
dalam menjalankan usaha ikan asin jambal roti di Karangsong Kabupaten Indramayu, diperlukan upaya agar penanganan dan pengolahan dilakukan dengan penerapan sistem manajemen mutu dan standardisasi mutu hasil perikanan dengan prospek yang masih cerah, karena produksi ikan manyung di Kabupaten Indramayu mencapai rata rata 5.000 ton/tahun (Dinas Perikanan dan Kelautan Kabupaten Indramayu 2018). Tujuan dari penelitian ini adalah menentukan strategi yang tepat untuk mengembangkan mutu ikan asin jambal roti di Kabupaten Indramayu diperlukan agar usaha ikan asin jambal roti di Karangsong Kabupaten Indramayu bisa berkembang lebih baik.

\section{BAHAN DAN METODE Waktu dan Lokasi Penelitian}

Penelitian inidilaksanakan diKarangsong, Kabupaten Indramayu, Provinsi Jawa Barat. Secara geografis, lokasi ini berada pada $6^{\circ} 18^{\prime} 50.5^{\prime \prime S}-108^{\circ} 20^{\prime} 59.7^{\prime \prime E}$. Waktu penelitian berlangsung mulai bulan September 2019 sampai bulan Februari 2020.

Kabupaten Indramayu memiliki jumlah produksi tangkapan laut sebesar 134.713 ton, dari 34 jenis spesies hasil tangkapan. Khusus untuk ikan manyung yang digunakan sebagai bahan ikan asin jambal roti tercatat sebanyak $13.161,51$ ton atau sebesar $9,77 \%$ dari total jumlah produksi tangkapan laut di Kabupaten Indramayu (Dinas Perikanan dan Kelautan Kabupaten Indramayu 2018).

\section{Jenis dan Metode Pengumpulan Data}

Jenis data yang digunakan dalam penelitian ini adalah data primer terkait pengembangan mutu ikan asin jambal roti di Karangsong Kabupaten Indramayu, Provinsi Jawa Barat. Data tersebut meliputi potensi yang merupakan kekuatan dari kegiatan usaha, kelemahan, ancaman yang dihadapi, serta peluang yang dapat dikembangkan dari usaha UMKM ikan asin jambal roti. Pengumpulan data dilakukan dengan wawancara mendalam dan observasi lapangan.

Metode pengambilan sampel yang digunakan adalah purposive sampling, yaitu dilakukan dengan mengambil data dari orangorang yang terpilih menurut peneliti, yang berhubungan dengan pengembangan usaha UMKM ikan asin jambal roti di Kabupaten Indramayu (Sugiyono 2016). Responden kunci tersebut berjumlah lima orang, yaitu terdiri dari pengawas perikanan, pembina mutu provinsi/daerah, pembina UMKM pengolah perikanan, akademisi, dan konsumen.

\section{Metode Analisis}

Metode analisis yang digunakan adalah kombinasi SWOT dan QSPM (Quantitative Strategic Planning Matrix). Metode SWOT digunakan untuk mengindentifikasi berbagai faktor SWOT secara sistematis untuk merumuskan strategi lembaga usaha (Rangkuti 2014), sedangkan metode QSPM digunakan untuk mengurutkan prioritas strategi yang sudah dihasilkan pada analisis SWOT, dengan cara menentukan daya tarik relatif (attractiveness score) yang didasarkan pada input dari bobot matriks internal dan eksternal, serta alternatif strategi pada tahap pencocokan (David et al. 2009; David 2011). Salah satu keunggulan QSPM adalah dapat diadaptasi dan digunakan untuk hampir semua tipe organisasi (David et al. 2009).

\section{HASIL DAN PEMBAHASAN Faktor Internal}

Hasil identifikasi faktor internal yang menjadi faktor kekuatan dari usaha ikan asin jambal roti di Kabupaten Indramayu adalah sebagai berikut :

1. Tersedianya tenaga kerja

Menurut Geffken et al. (2017), dalam usaha pengolahan ikan asin ada beberapa aspek yang penting, di antaranya adalah sarana, prasarana dan tenaga kerja. Tersedianya tenaga kerja di Kabupaten Indramayu menjadi salah satu faktor kekuatan yang dimiliki usaha ikan asin jambal roti. Tersedianya tenaga kerja mendukung pengembangan usaha pengolahan ikan asin.

2. Upah tenaga kerja lebih murah

Upah tenaga kerja menjadi salah satu faktor yang memengaruhi efisiensi kinerja suatu usaha pengolahan perikanan. Biaya upah tenaga kerja yang relatif murah memengaruhi nominal biaya proses produksi, muaranya adalah keuntungan usaha yang diperoleh bisa lebih tinggi (Sumantri et al. 
2016). Biaya upah tenaga kerja di Karangsong Kabupaten Indramayu tergolong relatif rendah, sehingga memberikan keuntungan dalam meminimalisasi biaya proses produksi.

3. Pengolah tekun dan ulet

Salah satu ciri dan watak seorang wirusaha yang sukses yaitu berorientasi pada tugas dan hasil, maksudnya bahwa tujuan kegiatan usaha yang dilakukan untuk mencapai prestasi dengan berorientasi untuk memperoleh laba. Untuk itu kegiatan usaha harus dilakukan dengan tekun, ulet, dan tekad kerja keras, serta mempunyai dorongan kuat dalam menjalankan usahanya (Winarto 2011). Para pengusaha ikan asin jambal roti di Kabupaten Indramayu juga tekun dan ulet dalam menjalankan usahanya, sehingga menjadi salah satu faktor kekuatan dalam keberlangsungan pengembangan usaha ikan asin jambal roti.

4. Proses pengolahan yang tidak rumit

Proses pengolahan ikan asin jambal roti yang tidak rumit menjadi salah satu faktor kekuatan dari usaha tersebut.

Hasil identifikasi faktor internal yang menjadi faktor kelemahan dari usaha ikan asin jambal roti di Kabupaten Indramayu adalah sebagai berikut:

1. Kurangnya kualitas SDM pelaku UMKM

Kurangnya kualitas SDM para pelaku UMKM menjadi salah satu kelemahan dari usaha ikan asin jambal roti di Kabupaten Indramayu. Pendidikan yang rata-rata rendah membuat mereka susah untuk berkembang dan sulit memahami aturan-aturan terkait pengolahan ikan.

2. Kurangnya kesadaran pelaku usaha UMKM tentang pentingnya SKP/SNI

Kurangnya kesadaran pelaku usaha UMKM tentang pentingnya SKP/SNI juga menjadi salah satu kelemahan yang dimiliki usaha ikan asin jambal roti di Kabupaten Indramayu. Hal tersebut berdampak pada keberlangsungan usaha. Usaha menjadi kurang berkembang karena tidak menerapkan manajemen mutu GMP SSOP.

3. Teknologi sederhana

Teknologi yang digunakan dalam usaha pembuatan ikan asin jambal roti di Kabupaten Indramayu masih sederhana. Hal tersebut menjadi salah satu kelemahan yang saat ini dimiliki usaha ikan asin jambal roti di Kabupaten Indramayu. Proses pengolahan masih bersifat tradisional, penerapan manajemen mutu GMP SSOP belum berjalan, sehingga kualitas produk kurang maksimal.

4. Kemasan kurang menarik

Kemasan produk yang kurang menarik menjadi salah satu kelemahan dari usaha ikan asin jambal roti di Kabupaten Indramayu. Mukhtar et al. (2015) melaporkan bahwa nilai produk dapat bertambah jika mengemasnya dengan menarik. Kemasan yang menarik akan memikat perhatian konsumen untuk membeli produk, sehingga mendukung perluasan pasar.

\section{Faktor Eksternal}

Hasil identifikasi faktor eksternal yang menjadi faktor peluang dari usaha ikan asin jambal roti di Kabupaten Indramayu adalah sebagai berikut:

1. Tersedianya peraturan perundangan lengkap

Tersedianya peraturan perundangundangan yang lengkap menjadi salah satu faktor peluang dari usaha UMKM ikan asin jambal roti di Kabupaten Indramayu. Dalam hal ini pemerintah mendukung usaha pengolahan ikan dalam menjamin mutu produk yang dihasilkan melalui UU Perikanan, peraturan-peraturan turunan di bawahnya, baik peraturan menteri, peraturan dirjen, dan lain-lain. Sehingga hal tersebut muaranya dapat membantu keberlangsungan usaha pengolahan ikan agar lebih baik lagi.

2. Tersedianya LS-ProHP di seluruh Indonesia

Pemerintah membentuk lembaga sertifikasi produk hasil perikanan (LS-ProHP) sebagai lembaga yang menangani tentang pencantuman logo atau tanda SNI pada produk hasil perikanan dan ada hampir di seluruh provinsi di Indonesia. Hal tersebut tentunya menjadi peluang bagi usaha pengolahan ikan atau UMKM ikan asin jambal roti, karena tidak perlu perjalanan jauh untuk mengakses lembaga sertifikasi produk hasil perikanan (LS-Pro HP).

3. Adanya pelanggan tetap

Adanya pelanggan tetap merupakan salah satu peluang yang dimiliki usaha ikan asin jambal roti di Kabupaten Indramayu. Lompoliuw et al. (2019) melaporkan bahwa 
mempertahankan pelanggan tetap jauh lebih menguntungkan bagi suatu perusahaan dari pada mencari pelanggan baru. Hal tersebut berarti adanya pelanggan tetap merupakan salah satu modal bagus yang dimiliki usaha pengolahan ikan asin jambal roti untuk bisa berkembang lebih baik.

4. Permintaan pasar yang tinggi

Adanya permintaan pasar yang tinggi juga merupakan peluang yang dimiliki usaha pengolahan ikan asin jambal roti, karena merupakan salah satu modal bagus untuk pengembangan usaha.

Hasil identifikasi faktor eksternal yang menjadi faktor ancaman dari usaha ikan asin jambal roti di Kabupaten Indramayu adalah sebagai berikut:

1. Terbatasnya anggaran kegiatan kementerian dan dinas terkait

Anggaran kegiatan dari kementerian dan dinas terkait terbatas. Hal tersebut dikarenakan banyaknya UMKM di setiap daerah, sehingga alokasi anggaran untuk setiap UMKM menjadi terbatas. Terbatasnya anggaran tersebut tentunya menjadi salah satu ancaman yang dihadapi usaha ikan asin jambal roti di Kabupaten Indramayu untuk berkembang.

2. Sosialisasi tentang pentingnya SKP/SNI masih kurang

Kegiatan sosialisasi tentang pentingnya SKP/SNI kepada para pelaku usaha pengolahan ikan di Kabupaten Indramayu masih kurang. Hal tersebut berakibat masih kurangnya kesadaran dan pemahaman dari para pelaku usaha pengolahan ikan akan pentingnya SKP/SNI bagi keberlangsungan usahanya.

3. Persyaratan untuk memperoleh SKP/SNI

masih terlalu susah untuk UMKM

Kendala utama usaha pengolahan ikan khususnya UMKM adalah persyaratan baik teknis maupun administrasi untuk menerapkan atau mendapatkan SKP masih terlalu sulit. Hal tersebut menjadi salah satu faktor ancaman dari usaha ikan asin jambal roti di Kabupaten Indramayu.

4. Banyaknya jumlah SNI dan UMKM Jumlah SNI dan UMKM produk perikanan di Indonesia jumlahnya banyak, hampir semua produk memiliki SNI, sehingga sektor mana yang terlebih dahulu diprioritaskan untuk dijadikan SNI wajib sulit dilakukan. Hal tersebut karena selama ini SNI produk perikanan masih bersifat sukarela penerapannya, dan belum menjadi kewajiban. Baru produk kemasan kaleng yang sudah wajib SNI.

\section{Matriks IFE (Internal Factor Evaluation)}

Hasil analisis matriks IFE (Table 1) menunjukkan bahwa untuk penilaian faktorfaktor kekuatan mendapatkan skor 1,484 dan untuk faktor-faktor kelemahan mendapatkan skor 1,785. Hal tersebut menunjukkan bahwa skor kelemahan yang dimiliki usaha UMKM ikan asin jambal roti di Kabupaten Indramayu lebih besar daripada kekuatan yang ada. Faktor internal dari usaha UMKM dalam pengembangan mutu ikan asin jambal roti di Kabupaten Indramayu dapat dilaksanakan dengan meminimalisiasi kelemahan yang ada, disertai dengan memanfaatkan segala kekuatan yaang dimiliki oleh usaha UMKM ikan asin jambal roti.

Nilai total dari skor terbobot matriks IFE adalah sebesar 3,269. Besaran nilai tersebut menunjukkan bahwa secara keseluruhan faktor internal yang dimiliki usaha UMKM cukup kuat untuk mendukung pengembangan mutu ikan asin jambal roti di Kabupaten Indramayu. Faktor kekuatan yang paling besar adalah proses pengolahan ikan asin jambal roti yang tidak rumit dengan skor terbobot 0,552, sedangkan faktor kelemahan yang paling tinggi adalah kurangnya kualitas SDM pelaku usaha UMKM serta kurangnya kesadaran pelaku usaha UMKM tentang pentingnya SKP/SNI, dengan skor sama yaitu terbobot 0,616 . Hal tersebut menunjukkan bahwa tidak rumitnya proses pengolahan ikan asin jambal roti merupakan faktor kekuatan yang paling berpengaruh dalam pengembangan mutu ikan asin jambal roti di Kabupaten Indramayu, sedangan kurangnya kualitas SDM pelaku usaha UMKM dan kurangnya kesadaran pelaku usaha UMKM tentang pentingnya SKP/SNI merupakan faktor kelemahan paling kuat dalam pengembangan mutu ikan asin jambal roti di Kabupaten Indramayu. 
Table 1 Internal factors evaluation matrix for quality development of salted jambal roti in Indramayu

\begin{tabular}{lccc}
\hline \multicolumn{1}{c}{ Parameter } & Weight & Rating & Score \\
\hline Strength & & & \\
Availability of labor & 0.123 & 3 & 0.369 \\
Cheap labor costs & 0.085 & 2 & 0.170 \\
Diligent and tenacious business manager & 0.131 & 3 & 0.393 \\
Easy processing & 0.138 & 4 & 0.552 \\
Subtotal & $\mathbf{0 . 4 7 7}$ & & $\mathbf{1 . 4 8 4}$ \\
Weaknesses & & & \\
The quality of human resources of SMEs is lacking & 0.154 & 4 & 0.616 \\
The awareness of MSME entrepreneurs about the importance of SKP / SNI & 0.154 & 4 & 0.616 \\
is still lacking & & & \\
Simple technology & 0.123 & 3 & 0.369 \\
Unattractive packaging & 0.092 & 2 & 0.184 \\
Subtotal & $\mathbf{0 . 5 2 3}$ & & $\mathbf{1 . 7 8 5}$ \\
Total & $\mathbf{1}$ & $\mathbf{3 . 2 6 9}$ \\
\hline
\end{tabular}

\section{Matriks EFE (External Factor Evaluation)}

Hasil analisis matriks EFE (Table 2) menunjukkan bahwa untuk penilaian faktorfaktor peluang mendapatkan skor 1,691 dan untuk faktor-faktor ancaman mendapatkan skor 1,556. Hal tersebut menunjukkan bahwa skor peluang yang dimiliki usaha UMKM ikan asin jambal roti lebih besar daripada ancaman yang dimiliki. Faktor eksternal dari usaha UMKM dalam pengembangan mutu ikan asin jambal roti di Kabupaten Indramayu dapat dilaksanakan dengan memanfaatkan peluang yang ada, disertai dengan meminimalisasi ancaman yang ada.

Nilai total dari skor terbobot matriks EFE adalah sebesar 3,247. Besaran nilai tersebut menunjukkan bahwa secara keseluruhan faktor eksternal yang dimiliki oleh usaha UMKM ikan asin jambal roti di Kabupaten Indramayu, cukup berpeluang untuk mendukung pengembangan mutu ikan asin jambal roti di Kabupaten Indramayu. Faktor peluang yang paling besar adalah permintaaan pasar akan ikan asin jambal roti yang tinggi, dengan skor terbobot 0,572 , sedangkan faktor ancaman yang paling tinggi adalah persyaratan untuk memperoleh SKP/SNI masih terlalu susah untuk UMKM, dengan skor terbobot 0,604. Hal tersebut menunjukkan bahwa tingginya permintaaan pasar akan ikan asin jambal roti sebagai faktor peluang yang paling berpengaruh dalam pengembangan mutu ikan asin jambal roti di Kabupaten Indramayu, sedangan terlalu susahnya persyaratan untuk memperoleh SKP/SNI untuk UMKM sebagai faktor ancaman paling kuat dalam pengembangan mutu ikan asin jambal roti di Kabupaten Indramayu.

\section{Prioritas Strategi Pengembangan Mutu Ikan Asin Jambal Roti di Kabupaten Indramayu}

Table 3 memperlihatkan urutan prioritas dari lima alternatif strategi pengembangan mutu ikan asin jambal roti di Kabupaten Indramayu. Pilihan strategi utama yang dinilai paling tinggi oleh para pakar adalah strategi W-O, yaitu meningkatkan mutu produk dan kualitas pelayanan kepada konsumen. Strategi tersebut memiliki jumlah total nilai daya tarik (Sum Total Attractive Score-STAS) tertinggi yaitu 5,2. Strategi tersebut adalah strategi yang bertujuan untuk meminimalisasi kelemahan internal, antara lain kurangnya kualitas SDM pelaku UMKM, teknologi yang digunakan masih sederhana, serta kemasan produk kurang menarik, dengan memanfaatkan peluang eksternal yang ada, di antaranya adalah tersedianya peraturan perundang- 
Table 2 External factors evaluation matrix for quality development of salted jambal roti in Indramayu

\begin{tabular}{lccc}
\hline \multicolumn{1}{c}{ Parameter } & Weight & Rating & Score \\
\hline Opportunities & & & \\
The availability of complete legislation & 0.119 & 3 & 0.357 \\
The availability of product certification organization throughout Indonesia & 0.119 & 3 & 0.357 \\
Permanent customers & 0.135 & 3 & 0.405 \\
High market demand & 0.143 & 4 & 0.572 \\
Subtotal & $\mathbf{0 . 5 1 6}$ & & $\mathbf{1 . 6 9 1}$ \\
Threats & & & \\
Limited budget for the activities of relevant ministries and departments & 0.095 & 2 & 0.190 \\
Socialization about the importance of INS is still lacking & 0.143 & 4 & 0.572 \\
Requirements for obtaining INS are still too difficult for MSMEs & 0.151 & 4 & 0.604 \\
Challenges to the large number of INS and MSMEs & 0.095 & 2 & 0.190 \\
Subtotal & $\mathbf{0 . 4 8 4}$ & & $\mathbf{1 . 5 5 6}$ \\
Total & $\mathbf{1}$ & $\mathbf{3 . 2 4 7}$ \\
\hline
\end{tabular}

undangan yang lengkap, tersedianya Ls-Pro HP di seluruh Indonesia, adanya pelanggan tetap, serta permintaan pasar yang tinggi.

Strategi tersebut juga hampir sama dalam rekomendasi hasil penelitian yang dilakukan oleh Niken et al. (2019) terkait pengembangan usaha pengolahan ikan jambal roti di Karangsong Kabupaten Indramayu. Salah satu hasil penelitian tersebut merekomendasikan bahwa peningkatan kuantitas dan kualitas produk, serta kegiatan pameran produk sangat diperlukan untuk keberlanjutan usaha pengolahan ikan jambal roti agar bisa berkembang dan memperluas pasar.

Kualitas produk dan kualitas pelayanan memberikan pengaruh yang positif terhadap kepuasan pelanggan (Ibrahim et al. 2019; Kamiludinsyah et al. 2015). Dengan penerapan manajemen mutu GMP SSOP dalam usaha ikan asin jambal roti di Kabupaten Indramayu, diharapkan dapat meningkatkan mutu produk dan kualitas pelayanan terhadap konsumen. Imbas positifnya adalah usaha UMKM ikan asin jambal roti di Kabupaten Indramayu dapat semakin berkembang dan semakin luas pangsa pasarnya.

Urutan berikutnya adalah tipe strategi $\mathrm{S}-\mathrm{O}$, yaitu penguatan dan pengembangan kelompok pengolahan ikan secara terpadu, dengan nilai STAS sebesar 5,090. Strategi tersebut merupakan strategi yang menggunakan kekuatan internal untuk meraih peluang sebesar-besarnya, yang ada di luar usaha UMKM ikan asin jambal roti. Niken et al. (2019) melaporkan bahwa strategi pengembangan kelompok usaha pengolahan ikan jambal roti di Karangsong Kabupaten Indramayu harus dilakukan untuk keberlanjutan dan pengembangan usaha tersebut.

Zakaria (2008) dalam penelitiannya menuturkan, penguatan dan pengembangan

Table 3 Priority strategy for quality development of salted jambal roti in Indramayu

\begin{tabular}{lcc}
\hline \multicolumn{1}{c}{ Strategies } & TAS & Priority \\
\hline Improving product quality and service quality to consumers (WO) & 5.200 & 1 \\
Strengthening and developing integrated fish processing groups (SO) & 5.090 & 2 \\
Socializing and training related to INS (WT1) & 4.889 & 3 \\
Facilitate the administration of the MSME fish processing industry (ST) & 4.879 & 4 \\
Looking for business partners for business development (WT2) & 4.790 & 5 \\
\hline
\end{tabular}


kelompok usaha secara terpadu dapat dilakukan melalui dukungan pemerintah, untuk meningkatkan nilai tambah suatu usaha dan mampu berdaya saing. Langkah yang dapat dilakukan adalah dengan cara pengembangan SDM, pengembangan teknologi, pengembangan jaringan kemitraan bisnis, dan peningkatan daya saing. Perhatian pemerintah dalam penguatan dan pengembangan kelompok pengolahan ikan secara terpadu dapat dilakukan sesuai langkah-langkah tersebut yang terkait dengan peningkatan mutu produk ikan asin jambal roti sesuai dengan Standar Nasional Indonesia.

Strategi W-T1 berada pada urutan prioritas ketiga, yaitu melakukan sosialisasi dan pelatihan terkait SKP/SNI, dengan nilai STAS sebesar 4,889. Strategi tersebut merupakan strategi untuk meminimalisasi kelemahan internal serta menghindari ancaman dari eksternal usaha UMKM ikan asin jambal roti. Kelemahan internal berupa kurangnya kualitas SDM pelaku UMKM, kurangnya kesadaran pelaku usaha UMKM tentang pentingnya SKP/SNI, dan kemasan produk yang kurang menarik dapat diminimalisasi dengan kegiatan sosialisasi dan pelatihan terkait SKP/SNI. Dengan strategi tersebut, ancaman eksternal berupa permasalahan kurangnya sosialisasi tentang pentingnya SKP/SNI, terlalu sulitnya persyaratan untuk memperoleh SKP/SNI untuk UMKM, serta tantangan jumlah SNI dan UMKM yang banyak, diharapkan dapat mampu dihindari.

Strategi yang hampir sama juga direkomendasikan dalam penelitian yang dilakukan oleh Niken et al. (2019) terkait pengembangan usaha pengolahan ikan jambal roti di Karangsong Kabupaten Indramayu. Kegiatan pelatihan pada kelompok usaha sangat diperlukan untuk keberlanjutan usaha pengolahan ikan jambal roti. Hal tersebut salah satunya karena kurangnya kualitas SDM dari para pelaku usaha UMKM.

Sampai saat ini di Karangsong Kabupaten Indramayu, untuk kegiatan sosialisasi dan pelatihan pada UMKM pengolahan perikanan sangat kurang, terutama terkait SKP/SNI. Ditambah kurangnya kualitas SDM dari para pelaku UMKM, serta kurangnya kesadaran dari para pelaku usaha UMKM tentang pentingnya SKP/SNI, sehingga penerapan SKP/SNI pada usaha ikan asin jambal roti skala UMKM di Karangsong Kabupaten Indramayu belum berjalan dengan baik. Maka diharapkan ke depan, kegiatan sosialisasi dan pelatihan terkait SKP/SNI dapat rutin dijalankan.

Urutan prioritas strategi yang keempat adalah tipe strategi S-T, yaitu mempermudah akses administrasi industri pengolahan ikan UMKM, dengan nilai STAS sebesar 4,879. Strategi tersebut bertujuan untuk meminimalisasi dampak ancaman dari eksternal usaha UMKM ikan asin jambal roti. Ancaman tersebut diantaranya adalah persyaratan untuk memperoleh SKP/SNI masih dianggap terlalu susah untuk para pelaku UMKM, serta tantangan jumlah SNI dan UMKM yang banyak, sehingga salah satu cara meminimalisasi adalah dengan mengimplementasikan strategi tersebut.

Urutan prioritas strategi yang terakhir adalah tipe strategi W-T2, yaitu mencari mitra usahauntukpengembanganusaha, dengannilai STAS sebesar 4,79. Pengembangan kemitraan merupakan salah satu cara yang dapat ditempuh untuk menjamin keberlangsungan usaha di sektor perikanan. Selain meningkatkan pendapatan, pengembangan kemitraan juga dapat melepas ketergantungan pelaku usaha perikanan terhadap lembaga permodalan tradisional, dan sebagai sarana untuk mencapai pembangunan yang lebih adil dan berkelanjutan. Pengembangan kemitraan tersebut dapat dilakukan jika terdapat sinergi antara pemerintah daerah, dunia usaha dan kelompok pelaku usaha (Asiati et al. 2016).

Nurhidayati et al. (2016) menambahkan, strategi bentuk kemitraan UMKM pengolahan ikan tersebut merupakan upaya dalam meningkatkan atau mengembangkan usaha pengolah ikan agar mampu berdaya saing tinggi dan mempunyai nilai tambah di pasar nasional maupun mampu masuk pasar internasional. Dalam penerapan strategi tersebut bisa dilakukan salah satunya melalui peran pemerintah berupa dukungan permodalan, yaitu mencarikan mitra usaha perbankan melalui kemudahan dalam mendapatkan pinjaman dari perbankan. 


\section{KESIMPULAN}

Strategi untuk mengembangkan mutu ikan asin jambal roti di Karangsong Kabupaten Indramayu berdasarkan urutan prioritas yaitu (1) meningkatkan kualitas produk dan mutu pelayanan kepada konsumen; (2) penguatan dan pengembangan kelompok pengolahan ikan secara terpadu; (3) melakukan sosialisasi dan pelatihan terkait SKP/SNI; (4) mempermudah akses administrasi industri pengolahan ikan UMKM; dan (5) mencari mitra usaha untuk pengembangan usaha.

\section{UCAPAN TERIMA KASIH}

Ucapan terima kasih kami tujukan kepada seluruh dosen dan civitas academica Fakultas Perikanan dan Ilmu Kelautan Universitas Diponegoro Semarang, seluruh pegawai di instansi Dinas Kelautan dan Perikanan Kabupaten Indramayu, Lembaga Sertifikasi Produk Hasil Perikanan UPTD Pengujian dan Penerapan Mutu Produk Perikanan (PPMPP) Cirebon, para pengelola usaha UMKM ikan asin jambal roti di Karangsong Kabupaten Indramayu, dan semua pihak yang sudah berpartisipasi selama kegiatan penelitian dan penulisan artikel ini.

\section{DAFTAR PUSTAKA}

Asiati D, Nawawi. 2016. Kemitraan di sektor perikanan tangkap: strategi untuk kelangsungan usaha dan pekerjaan (partnership in the fishery sector: strategies for business and employment sustainability). Jurnal Kependudukan Indonesia. 11(2): 103-118.

Akbardiansyah, Desniar, Uju. 2018. Karakteristik ikan asin kambing-kambing (Canthidermis maculata) dengan penggaraman kering. Jurnal Pengolahan Hasil Perikanan Indonesia. 21(2): 345355.

Amin MZ, Nugroho LPE, Nurjanah. 2018. Kajian implementasi GMP dan SSOP ikan teri nasi setengah kering di Kabupaten Tuban. Jurnal Pengolahan Hasil Perikanan Indonesia. 21(3): 406-413

Anggraeni D, Nurjanah, Asmara DA, Hidayat T. 2019. Kelayakan industri pengolahan ikan dan mutu produk UMKM pindang tongkol di Kabupaten Banyuwangi. Jurnal
Pengolahan Hasil Perikanan Indonesia. 22(1): 14-23.

David ME, David RF, David FR. 2009. The quantitative strategic planning matrix (qspm) applied to retail computer store. The Coastal Business Journal. 8(1): 42- 52.

David FR. 2011. Strategic Management (Concepts and Cases). New Jersey (US): Pearson Education, Inc.

Dinas Perikanan dan Kelautan Kabupaten Indramayu. 2018. Data Statistik Produksi dan Nilai Produksi Perikanan dan Kelautan Tahun 2014 - 2017 (Dinas Perikanan dan Kelautan Kabupaten Indramayu). Dinas Perikanan dan Kelautan Kabupaten Indramayu.

Geffken R, Hendrik, Zulkarnain. 2017. Analisis usaha pengolahan ikan asin di Kelurahan Pondok Batu Kecamatan Sarudik Kota Sibolga Provinsi Sumatera Utara. Jurnal Online Mahasiswa. 4(1): 1-9.

Ibrahim M, Thawil SM. 2019. Pengaruh kualitas produk dan kualitas pelayanan terhadap kepuasan pelanggan. Jurnal Riset Manajemen dan Bisnis (JRMB) Fakultas Ekonomi UNIAT. 4(1): 175 - 182.

Kamiludinsyah M, Fadillah A. 2015. Pengaruh kualitas produk dan kualitas pelayanan terhadap kepuasan pelanggan. [diunduh 2020 April 2]. Tersedia pada: https://www. researchgate.net/publication/328849864. 2015.

Liufeto DS, Darmanto YS, Agustini TW. 2016. Kualitas pengolahan ikan kayu di Kabupaten Sikka. Prosiding Seminar Nasional Kelautan Universitas Trunojoyo Madura. Madura, Indonesia. Madura (ID): Hlm 295-300.

Lompoliuw TSM, Riane JP, Roy FR. 2019. Faktor-faktor yang mempengaruhi customer retention di PT. Erafone Mega Mall Manado. Jurnal Administrasi Bisnis. 9(1): 114-121.

Maulid DY, Abrian S. 2020. Kandungan garam dan komposisi proksimat ikan asin jambal roti (Arius thalassinus) dari Pangandaran. Marlin. 1(1):1-6

Mukhtar, Syukrianti, Nurif M. 2015. Peranan packaging dalam meningkatkan hasil produksi terhadap konsumen. Jurnal Sosial Humaniora. 8(2): 181-191. 
Niken T, Nurcahya DE, Winarni AT. 2019. Sustainability analysis of jambal roti business as superior product from Indramayu, West Java of Indonesia. Eurasia: Economics \& Business. 8(26): 5262.

Nurhidayati A, Rikah. 2016. Strategi kemitraan UMKM pengolah ikan di Kabupaten Rembang. Buletin Bisnis \& Manajemen. 2(1): 1-8.

Paladini EP, Avilés BG, Schumacher L, Lorenz M, Urquiza YR. 2019. Quality management model for perishable food in a fishing industry. Journal of Food Process Engineering.13171: 1-17.

Rangkuti F. 2006. Analisis SWOT Teknik Membedah Kasus Bisnis. Jakarta (ID): PT Gramedia Pustaka Utama.

Rangkuti F. 2014. Teknik Membedah Kasus Bisnis: Analisis SWOT (Cara Perhitungan Bobot, Rating, dan OCAI). Jakarta (ID): PT Gramedia Pustaka Utama.
Rochima E. 2005. Pengaruh fermentasi garam terhadap karakteristik jambal roti. Buletin Teknologi Hasil Perikanan. 8(2): 46-56.

Sumantri B, Purwoko A, Sriyoto. 2016. Analisis kinerja usaha pembuatan ikan kering di Kota Bengkulu. AGRISEP. 16(1): 15 - 26.

Sugiyono. 2016. Metodologi Penelitian Kuantitatif Kualitatif dan R\&D. Bandung (ID): Penerbit Alfabeta.

Winarto H.2011. Menuju sukses berwirausaha. Majalah Ilmiah Ekonomika. 14(1): 1 - 38.

Zakaria WA. 2008. Penguatan kelembagaan kelompok tani kunci kesejahteraan petani. Seminar Nasional Dinamika Pembangunan Pertanian dan Pedesaan; 2008 Nop 19; Bogor, Indonesia. Bogor (ID): Pusat Analisis Sosial Ekonomi dan Kebijakan Pertanian Departemen Pertanian. Hlm 1-20; [diunduh 2020 Mar 7]. Tersedia pada: pse.litbang.pertanian. go.id/ind/pdffiles/MS_C3.pdf. 